\title{
Knowledge and Practices of Mutawifeen (Pilgrims' Guides) Regarding Heat Related IIInesses Before and After Exposure to an Educational Program
}

\author{
Mohammad M. Alkot ${ }^{1,}$, , Reda A. Goweda ${ }^{2}$, Mokhtar M. Shatla ${ }^{1}$, Enas H. AlFalogy ${ }^{2}$ \\ ${ }^{1}$ Family Medicine Department, Menoufia University, Shebien Elkoum, Egypt \\ ${ }^{2}$ Family Medicine Department, Suez Canal University, Ismalia, Egypt \\ Email address: \\ Mohammed_elkott@yahoo.com (M. M. Alkot), Redagoweda@yahoo.com (R. A. Goweda), Mokhtarshatla@gmail.com (M. M. Shatla), \\ Enas_Hamdy2007@yahoo.com (E. H. AlFalogy)
}

\section{To cite this article:}

Mohammad M. Alkot, Reda A. Goweda, Mokhtar M. Shatla, Enas H. AlFalogy. Knowledge and Practices of Mutawifeen (Pilgrims' Guides) Regarding Heat Related Illnesses Before and After Exposure to an Educational Program. European Journal of Preventive Medicine. Vol. 4, No. 4, 2016, pp. 95-99. doi: 10.11648/j.ejpm.20160404.11

Received: February 26, 2016; Accepted: March 22, 2016; Published: June 4, 2016

\begin{abstract}
Pilgrims who are exposed to hot environments may be at risk of heat-related illnesses (HRIs) such as heat cramps, heat exhaustion, or heat stroke. Mutawifeen (pilgrims' guides) should understand how HRIs affect pilgrims' health and safety, how they can be prevented, and what the initial treatment options are. The study Objectives is to assess and improve knowledge and practices of Mutawifeen towards HRIs. An intervention study was conducted before the pilgrimage of the year 1437 Hijri calendar (2015) on a group of Mutawifeen (No.200) in Makkah Al-Mukaramh, KSA. The participants were invited after their consent to fill a self-administrated questionnaire before and 3 months after their exposure to an education program (academic and clinical). At the end of the study, the score of knowledge and practices were significantly improved (52.68 \pm 14.92 and $49.6 \pm 12.84$ to $74.54 \pm 10.97$ and $65.78 \pm 7.83$; respectively). There was statistically moderate positive correlation between knowledge and practices $(\mathrm{r}=0.426 ; \mathrm{p}<0.01)$. The percentage of participants with correct knowledge and appropriate practices has significantly increased from $46 \%$, and $39.5 \%$ before education to $89 \%$, and $72.5 \%$ after education, respectively $(\mathrm{P}<0.05)$. The study conclude that, academic and clinical education of Mutawifeen is a cornerstone in improving their Knowledge and Practices towards HRIs.
\end{abstract}

Keywords: Heat-Related Illnesses, Mutawifeen, Educational Program, Knowledge, Practices

\section{Introduction}

The Muslim Pilgrimage to Makkah (Hajj) is one of the Five Pillars of the Islamic Religion and it is the duty of every Muslim to perform it once [1]. All the rites of the Hajj entail strenuous physical effort. [2] Throughout the hot months of May to September, the temperature ranges between $38^{\circ} \mathrm{C}$ and $50^{\circ} \mathrm{C}$ with a relative humidity of $25 \%$ to $50 \%$. This kind of hot environment with high radiant heat favors the development of heat related illnesses (HRI) during Hajj [3]. Heat-related illnesses (HRI) are a group of preventable conditions that range from mild forms (e.g., heat cramps, heat exhaustion) to the potentially fatal condition, heat stroke. Mortality increases in relation to a heat index higher than $95^{\circ} \mathrm{F}\left(35^{\circ} \mathrm{C}\right)$, and duration of heat exposure [4]. There were 8015 deaths attributed to HRI from 1979-2003, or an average of approximately 334 deaths per year [5]. Populations at increased risk include elderly people, children, and persons who perform strenuous outdoor activities. Persons with chronic heart and lung diseases, chronic mental disorders, and those taking diuretics that interfere with salt and water balance are also at increased risk [6].

Mild forms of HRIs are characterized by a core body temperature lower than $104^{\circ} \mathrm{F}\left(40^{\circ} \mathrm{C}\right)$ and without symptoms of central nervous system disturbances. These forms include heat cramps, syncope, and exhaustion. In absence of abnormal mental status, these conditions can only be differentiated from early signs of the more serious heat stroke 
by obtaining an accurate measure of core body temperature. A rectal temperature is considered the most reliable measurement because other alternatives, including oral, axillary, tympanic, and skin temperatures, are less accurate [7]. Patients with heat exhaustion should be moved to a shaded, cool environment, get their excess clothing removed, and placed in a supine position, preferably with their legs elevated, and fluids for rehydration [8].

Heat stroke is characterized by an elevated core body temperature of $104^{\circ} \mathrm{F}\left(40^{\circ} \mathrm{C}\right)$ or above, dry skin, and associated mental abnormalities [9]. It is a true emergency that requires immediate recognition and treatment. Treatment begins with stabilizing the patient's airway, breathing, and circulation (ABC guide). Cold water immersion is the treatment of choice when available. Applying ice packs or cold, wet towels to the head, neck, axilla, and groin is an alternative option in absence of cold water immersion [10]. Prevention of HRIs during heat exposure activities should include; identify older patients with chronic medical disease and other populations at risk, avoiding medications that can increase the risk of heat illness (e.g. antihypertensives, diuretics, and anticholinergics), gradual adjustment to heat, and sufficient fluids and electrolytes, and make cool facilities available during exposure [11]. Physicians can work with community leaders to provide the preventive services [12].

Mutawifeen are a group of guides to Muslim pilgrims that help them to perform their Hajj rites. They are also required to provide preventive and first aid measures for some common health problems during Hajj. Although HRIs are common health problems and sometimes fatal, there were a great shortage in studying knowledge and practices of Mutawifeen regarding this problem until now. The objectives of this study is to assess and improve knowledge and practices of Mutawifeen regarding HRIs.

\section{Subjects and Methods}

An intervention study was conducted before the pilgrimage of the year 1437 Hijri calendar (2015) on a group of Mutawifeen (No.200) in Makkah Al-Mukaramh, KSA. The participants were invited after their consent to fill a selfadministrated questionnaire before and 3 months after their exposure to an education program (academic and clinical). An Arabic closed ended questionnaire was designed by the researchers to collect information about: 1. knowledge assessment regarding HRIs e.g.: Types, signs and symptoms, risk factors, preventive measures, first aids ...etc. 2 . Practices including educating pilgrims on causes and preventive measures, early recognition, proper testing of temperature, rapid cooling measures, and other first aid practices. The same questionnaire was used as a pre and post-test, before and three months after conducting the education program. Pilot study was done before intervention on $20(10 \%$ of the study population) to ensure validity and standardization, highlight problems with data collection. Mutawifeen were invited to participate in the study and respond to the questionnaire items after the aim and methods of the study were simply explained to obtain their consent. Analysis of the collected data was done to identify weaknesses/strengths in knowledge and practices of the participants. An education program was designed based on data analysis to emphasize on the weaknesses and augment the strengths. Participants were then invited to attend the education program. The program consists of academic preparation and clinical education about HRIs with special emphasis on prevention, population at risk, early signs and symptoms, discrimination between heat exhaustion and stroke, first aid measures....etc. The program was conducted as lectures; small and large group discussion and roleplaying. Photos, posters, pamphlets, data show and dummies were used as teaching aids. The program was evaluated three months later by post-test using the same pre-test questionnaire. Questions measuring knowledge with correct statement were scored (1) for correct answer and (0) for incorrect whereas other questions with wrong statement were scored as (0) for correct and [1] for incorrect while practices' questions were scored as (3) always, (2) usual, (1) rarely and (0) never. Cutoff point for good knowledge and appropriate practices was set at $60 \%$.

\section{Statistical Analysis}

The results were collected, tabulated and statistically analyzed by SPSS software program (Statistical Program for Social Science), Version 20. Quantitative data were expressed as mean and standard deviation. Qualitative data were expressed as numbers and percentages. To assess the differences in frequencies on the dichotomized qualitative variables (scored present or absent) Chi-Square test $\left(\chi^{2}\right)$ was used with $5 \%$ level of significance. Correlation between knowledge and practices was done using Spearman's correlation test.

\section{Results}

Total number of Mutawifeen who participated in this study was 200 and were tested for knowledge and practices before and after education. The most notable and disconcerting result of this study was the poor level of both knowledge and practices before education that have been significantly improved after education (52.68 \pm 14.92 and $49.6 \pm 12.84$ before education, to $74.54 \pm 10.97$ and $65.78 \pm 7.83$ after education; respectively). The percentage of participants with correct knowledge and appropriate practices has significantly improved from $46 \%$ and $39.5 \%$ before education, to $89 \%$ and $72.5 \%$ after education; respectively $(\mathrm{P}<0.05)$. Regarding knowledge, there was significant improvement in all parameters after exposure except for the initial management of HRI by rapid cooling measures ( $p$ value 0.444 ). (Table 1 ) Regarding practices, there was highly significantly improvement after exposure (Table 2). There was a moderate positive correlation between knowledge and practices after education $(\mathrm{r}=0.426 ; \mathrm{p}<0.01)$. 
Table 1. Correct knowledge of Motawifeen regarding heat related illnesses before and after education.

\begin{tabular}{|c|c|c|c|}
\hline \multirow{2}{*}{ Knowledge parameters } & \multicolumn{2}{|l|}{ Education } & \multirow{2}{*}{ P value } \\
\hline & Pre-exposure (No.200) & Post-exposure (No.200) & \\
\hline Normal body temperature less than 37.5 & $146(73.0 \%)$ & $162(81.0 \%)$ & 0.037 \\
\hline Heat related illnesses might lead the pilgrim to a rapid loss of his life & $117(58.5 \%)$ & $155(77.5 \%)$ & 0.000 \\
\hline $\begin{array}{l}\text { All people from all age groups and health status are equally at the same level of risk of } \\
\text { developing heat related illnesses }\end{array}$ & $69(34.5 \%)$ & $130(65.0 \%)$ & 0.000 \\
\hline There is only one clinical form of heat related illness & $64(32.0 \%)$ & $141(70.5 \%)$ & 0.000 \\
\hline Muscle cramps in pilgrims could be due to heat related illnesses & $96(48.0 \%)$ & $157(78.5 \%)$ & 0.000 \\
\hline Nausea and vomiting could be due to heat related illness & $67(33.5 \%)$ & $135(67.5 \%)$ & 0.000 \\
\hline Fainting and collapse could be due to heat related illness & $145(72.5 \%)$ & $162(81.0 \%)$ & 0.029 \\
\hline Heat exhaustion is characterized by dry skin & $94(47.0 \%)$ & $132(66.0 \%)$ & 0.000 \\
\hline Heat exhaustion is characterized by temperature higher than 40 degrees & $74(37.0 \%)$ & $136(68.0 \%)$ & 0.000 \\
\hline Heat stroke is characterized by wet skin & $81(40.5 \%)$ & $139(69.5 \%)$ & 0.000 \\
\hline Heat stroke is characterized by temperature higher than 40 degrees & $88(44.0 \%)$ & $163(81.5 \%)$ & 0.000 \\
\hline $\begin{array}{l}\text { When heat exhaustion is suspected, temperature could be assessed orally, axillary or } \\
\text { rectally }\end{array}$ & $106(53.0 \%)$ & $156(78.0 \%)$ & 0.000 \\
\hline $\begin{array}{l}\text { Muscle relaxants are the essential treatment of muscle cramps rather than rest in a cool } \\
\text { place and drink fluids. }\end{array}$ & $114(57.0 \%)$ & $134(67.0 \%)$ & 0.025 \\
\hline $\begin{array}{l}\text { Heat exhaustion is managed by transfer of the pilgrim to a cool environment, drink } \\
\text { fluids, apply cool water or ice packs, fanning }\end{array}$ & $170(85.0 \%)$ & $172(86.0 \%)$ & 0.444 \\
\hline Cool water and Ice packs are applied to the victim's head and feet to cool him rapidly & $96(48.0 \%)$ & $138(69.0 \%)$ & 0.000 \\
\hline $\begin{array}{l}\text { When heat stroke is suspected, you first transfer the victim to a cool environment then } \\
\text { ask for an ambulance }\end{array}$ & $77(38.5 \%)$ & $152(76.0 \%)$ & 0.000 \\
\hline $\begin{array}{l}\text { When heat stroke is suspected, you should follow the } \mathrm{ABCD} \text { guide to manage the } \\
\text { victims condition }\end{array}$ & $112(56.0 \%)$ & $143(71.5 \%)$ & 0.001 \\
\hline
\end{tabular}

Table 2. Appropriate practices of Motawifeen regarding heat related illnesses before and after exposure to the education.

\begin{tabular}{|c|c|c|c|}
\hline \multirow{2}{*}{ Practices parameters } & \multicolumn{2}{|l|}{ Education } & \multirow{2}{*}{ Pvalue } \\
\hline & Pre-exposure (No.200) & Post-exposure (No.200) & \\
\hline You educate pilgrims on causes of heat related disorders & $135(67.5 \%)$ & $173(86.5 \%)$ & 0.000 \\
\hline You educate pilgrims preventive measures to prevent heat related illness & $143(71.5 \%)$ & $182(91.0 \%)$ & 0.000 \\
\hline You educate pilgrims on early symptoms of heat related illness & $67(33.5 \%)$ & $155(77.5 \%)$ & 0.000 \\
\hline $\begin{array}{l}\text { you review your group of pilgrims to identify those at risk for developing heat related } \\
\text { disorders (children, old ages) }\end{array}$ & $73(36.5 \%)$ & $164(82.0 \%)$ & 0.000 \\
\hline you provide them umbrellas and cold water bottles & $28(14.0 \%)$ & $38(19.0 \%)$ & 0.044 \\
\hline $\begin{array}{l}\text { You closely watch your group of pilgrims to early identify those at risk (e.g. walking } \\
\text { on sun without umbrellas) }\end{array}$ & $62(31.0 \%)$ & $102(51.0 \%)$ & 0.000 \\
\hline You consider those with cramps as having heat related illness & $56(28.0 \%)$ & $99(49.5 \%)$ & 0.000 \\
\hline You test temperature rectally & $29(14.5 \%)$ & $58(29.0 \%)$ & 0.000 \\
\hline $\begin{array}{l}\text { You transfer every pilgrim who faints to the nearby health station after immediate } \\
\text { first aids }\end{array}$ & $136(68.0 \%)$ & $195(97.5 \%)$ & 0.000 \\
\hline
\end{tabular}

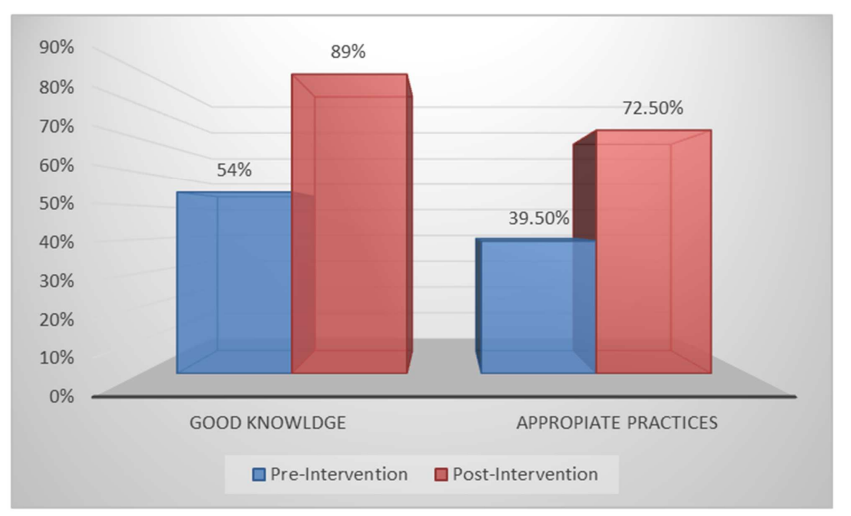

Figure 1. Total scores percentage of good KNOWLEDGE and APPROPRIATE practices before and after education.

\section{Discussion}

Because HRIs occur frequently in environments similar to Pilgrimage, like athletic and military exercise settings, many other researchers have sought to reduce or prevent the mortalities related to this problem. A relation between HRIs mortalities and inappropriate practices and medical care has been suggested by previous researchers [13] and therefore served as the motive for this study. In the current study, there was significant improvement of knowledge and practices after exposure to the educational program. This improvement is due to conduction of a structured, both academic and clinical education which stressed on the weak areas of knowledge and practices that have been identified in the pre-education phase 
of the study. Many other studies suggested the positive effect of educational program on improvement of knowledge and practices $[14,15,16,17,18,19]$. There was overall poor level of practices before education. This is explained by lack of clinical education in the pre-education phase of the study. Lack of clinical education, skill expertise, lack of familiarity, confidence in abilities, [20] and practice style traits [21] have all been documented as influencing a medical professional's use of evidence-based practice. There was significant statistical improvement in practices after education. This is explained by the clinical component of the educational program which improved their level of competence and confidence with improved skills and familiarity with the clinical situation. Another explanation is the improved knowledge as this study showed a moderate positive correlation between knowledge and practices after education. This finding coincides with many studies which support the positive correlation between knowledge and practices [22, 23, 24, 25, 26, 27]. However, Mazerolle et al. [28], found a gap between knowledge and practices where they studied a group of athletic trainers who showed that, although $77.1 \%$ of trainers had read the latest National Athletic Trainers' Association( NATA) [29] position statement on exertional HRIs and could correctly identify the most valid temperature assessment devices and treatment options, many were not following these recommended guidelines, a finding comparable with the results generated by the pilot study of Dombek et al. [13].

Although the study showed post-education improvement in all aspects of practices, still there were inappropriate practices after education especially as regard using thermometers other than the rectal thermometer for testing core body temperature. This might be explained by lack of the equipment of rectal thermometers, and cultural factors as they might consider testing temperature through the pilgrim's rectum breaches the pilgrim's dignity. They might prefer to delegate this role to professional health care workers after transfer to health stations. This coincides with a study by Mazerolle et al., where less than one-fifth of athletic trainers used rectal thermometers to assess core body temperature, and only one-half used cold-water immersion to treat exertional heat stroke.

\section{Conclusion}

Academic and clinical education of Mutawifeen improves their knowledge and practices regarding HRIs during Hajj. There was an association between knowledge and practices, where the improved knowledge was accompanied by improved practices.

\section{Recommendation}

Clinical education should be an integral part of educating Mutawifeen as regard HRIs and other Hajj related medical problems. Continuous education is recommended to maintain the gain and for continuous improvement.

\section{Limitations of the Study}

-This is an initial attempt to assess HRIs knowledge and practices among Mutawifeen

-Lack of direct observation of their practices in the field of pilgrimage because of the overcrowdings and the nature of the Hajj rituals; rather, using a self-administered questionnaire for the feasibility of study. Larger studies are needed to include a larger sample, and in situ observation of their practices.

\section{References}

[1] El Halawani A W. Heat illness during the Mecca pilgrimage. WHO Chronicle 1964; 18: 2838.

[2] Sardar Z. The Spiritual and Physical Dimensions of HAJJ: In Hajj studies Vol I. Sardar Z and Badawi M A Z (eds) Croom Helm. London, p 28, 1978.

[3] Khogali M and Alkhawashki M I. Heat stroke during the Makkah pilgrimage (Hajj). Saudi Medical Journal 1981; 2: 85-93.

[4] JONATHAN A. BECKER, MD and LYNSEY K. STEWART, MD, University of Louisville, Louisville, Kentucky. HeatRelated Illness. Am Fam Physician. 2011 Jun 1; 83(11): 13251330.

[5] Centers for Disease Control and Prevention. Extreme Heat: A Prevention Guide to Promote Your Personal Health and Safety. Reviewed May 31, 2012. Available athttp://emergency.cdc.gov/disasters/extremeheat/heat_guide.a sp. Accessed: May 1, 2015.

[6] Glazer JL. Management of heatstroke and heat exhaustion. Am Fam Physician. 2005; 71(11): 2133-2140.

[7] Casa DJ, McDermott BP, Lee EC, Yeargin SW, Armstrong LE, Maresh CM. Cold water immersion: the gold standard for exertional heatstroke treatment. Exerc Sport Sci Rev. 2007; 35(3): 141-149.

[8] Armstrong LE, Casa DJ, Millard-Stafford M, Moran DS, Pyne SW, Roberts WO; American College of Sports Medicine. American College of Sports Medicine position stand. Exertional heat illness during training and competition. Med Sci Sports Exerc. 2007; 39(3): 556-572.

[9] Bouchama A, Knochel JP. Heat stroke. N Engl J Med. 2002; 346(25): 1978-1988.

[10] Bytomski JR, Squire DL. Heat illness in children. Curr Sports Med Rep. 2003; 2(6): 320-324.

[11] Lipman, GS; Eifling, KP; Ellis, MA; Gaudio, FG; Otten, EM; Grissom, CK; Wilderness Medical, Society (December 2013). "Wilderness Medical Society practice guidelines for the prevention and treatment of heat-related illness." Wilderness \& environmental medicine 24 (4): 351-61.

[12] Centers for Disease Control and Prevention (CDC). Heatrelated deaths - four states, July-August 2001, and United States, 1979-1999. MMWR Morb Mortal Wkly Rep. 2002; 51(26): 567-570. 
[13] Dombek P. M., Casa D. J., Yeargin S. W., et al. Athletic trainers' knowledge and behavior regarding the prevention, recognition, and treatment of exertional heat stroke at the high school level [abstract] J Athl Train. 2006; 41(suppl 2):S47.

[14] Eze CN, Ebuehi OM, Brigo F, Otte WM, Igwe SC. Effect of health education on trainee teachers' knowledge, attitudes, and first aid management of epilepsy: An interventional study. Seizure. 2015 Dec; 33: 46-53. doi: 10.1016/j.seizure.2015.10.014. Epub 2015 Nov 1.

[15] Cooper C, Huzzey L, Livingston G. The effect of an educational intervention on junior doctors' knowledge and practice in detecting and managing elder abuse. Int Psychogeriatr. 2012 Sep; 24(9): 1447-53. doi: 10.1017/S1041610212000403. Epub 2012 Mar 30.

[16] McNamara MC1, Harmon D, Saunders J. Effect of education on knowledge, skills and attitudes around pain. Br J Nurs. 2012 Sep 13-26; 21(16): 958, 960-4.

[17] Lin PC, Chiang HW, Chiang TT, Chen CS. Pain management: evaluating the effectiveness of an educational programme for surgical nursing staff. J Clin Nurs. 2008 Aug; 17(15): 203241 .

[18] Gustafsson M, Borglin G. Can a theory-based educational intervention change nurses' knowledge and attitudes concerning cancer pain management? A quasi-experimental design. BMC Health Serv Res. 2013 Aug 19; 13: 328. doi: 10.1186/1472-6963-13-328

[19] Richardson B, Kitchen G, Livingston G. The effect of education on knowledge and management of elder abuse: a randomized controlled trial. Age Ageing. 2002 Sep; 31(5): $335-41$.

[20] Cochrane L. J., Olson C. A., Murray S., Dupis M., Tooman T., Hayes S. Gaps between knowing and doing: understanding and assessing the barriers to optimal health care. J Contin Educ Health Prof. 2007; 27(2): 94-102.

[21] Korner-Bitensky N., Menon-Nair A., Thomas A., Boutin E., Arafah A. M. Practice style traits: do they help explain practice behaviors of stroke rehabilitation professionals? J Rehabil Med. 2007; 39: 685-692.
[22] Linus J. Dowell. The Relationship between Knowledge and Practice. The Journal of Educational Research. Vol. 62, No. 5 (Jan., 1969), pp. 201-205.

[23] Kelantan, Malaysia Ranimah Yahya, Rosediani Muhamad *, Harmy Mohamed Yusoff. Association between Knowledge, Attitude and Practice on Cardiovascular Disease among Women. International Journal of Collaborative Research on Internal Medicine \& Public Health. Vol. 4 No. 8 (2012)

[24] Jonathan Yap, Vernon J Lee, Teng Yan Yau, Tze Pin Ng and Phern-Chern Tor. Knowledge, attitudes and practices towards pandemic influenza among cases, close contacts, and healthcare workers in tropical Singapore: a cross-sectional survey. BMC Public Health201010: 442

[25] Abebe DS, Biffa D, Bjune G, Ameni G, Abebe F. Assessment of knowledge and practice about tuberculosis among eastern Ethiopian prisoners. Int J Tuberc Lung Dis 2011; 15(2): 22833.

[26] Launiala A, Honkasalo ML. Ethnographic study of factors influencing compliance to intermittent preventive treatment of malaria during pregnancy among Yao women in rural Malawi. Trans R Soc Trop Med Hyg 2007; 101(10): 980-9.

[27] Júnior SF, Oliveira HB, Marin-Léon L. Knowledge, attitudes and practices on tuberculosis in prisons and public health services Rev. bras. epidemiol. vol.16 no.1 São Paulo Mar. 2013.

[28] Mazerolle SM, Scruggs IC, Casa DJ, Burton LJ, McDermott BP, Armstrong LE, Maresh CM. Current Knowledge, Attitudes, and Practices of Certified Athletic Trainers Regarding Recognition and Treatment of Exertional Heat Stroke. J Athl Train. 2010 Mar-Apr; 45(2): 170-180.doi: 10.4085/1062-6050-45.2.170.

[29] Binkley H. M., Beckett J., Casa D. J., Kleiner D. M., Plummer P. E. National Athletic Trainers' Association position statement: exertional heat illnesses. J Athl Train. 2002; 37(3): 329-343. 